\title{
OBSERVATORIO
}

\section{COMUNICACIÓN DIGITAL. RECUERDOS DEL FUTURO}

\author{
Carlos A. Scolari
}

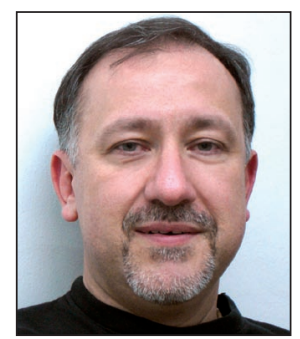

Carlos A. Scolari es doctor en lingüística aplicada y lenguajes de la comunicación por la Università Cattolica di Milano. Es profesor titular del Departamento de Comunicación en la Universitat Pompeu Fabra (UPF). Entre otras obras ha publicado Hacer clic. Hacia una socio-semiótica de las interacciones digitales (2004), Hipermediaciones. Elementos para una teoría de la comunicación digital interactiva (2008) y El fin de los medios masivos. El comienzo de un debate (con M. Carlón, 2009). Sus artículos han sido publicados en Communication theory, New media \& society, International journal of communication, Semiotica, Information, Communication \& society, Journal of visual literacy, Comunicación y sociedad, deSignis, Signo y pensamiento entre otras revistas científicas.

Departament de Comunicació, Universitat Pompeu Fabra Roc Boronat, 138. 08018 Barcelona, España http://www.hipermediaciones.com - http://www.digitalismo.com - http://www.modernclicks.net carlosalberto.scolari@upf.edu

\section{Resumen}

Se propone una reflexión sobre la emergencia de nuevas formas de comunicación digital interactiva a finales del siglo XX. Construido como si fuera un relato histórico escrito en el futuro, se describen las principales mutaciones vividas por el ecosistema de medios desde la irrupción de las tecnologías digitales y las redes globales. Desde una perspectiva histórica la época contemporánea se presenta como un período contradictorio y a menudo ininteligible similar a otras fases de transición, por ejemplo el Renacimiento (s. XV-XVI) o la Revolución industrial (s. XVIII-XIX). El texto también describe algunas de las consecuencias teóricas y los debates más destacados de ese período.

\section{Palabras clave}

Comunicación digital, Sociedad, Transformación social, Tecnologías de la información, Revolución digital, Ecosistema informativo, Redes sociales, Medios, Ecología de los medios.

\section{Title: Digital communication. Memories of the future}

\begin{abstract}
A reflection on the emergence of new forms of interactive digital media in the late twentieth century is proposed. Presented as a historical account written in the future, the main mutations experienced by the media ecosystem from the emergence of digital technologies and global networks are described. From a historical perspective the contemporary period is presented as an unintelligible and often contradictory period similar to other phase transitions, such as the Renaissance (XV-XVI century) or the Industrial Revolution (XVIII-XIX). The text also describes some of the theoretical implications and the most salient debates of that period.
\end{abstract}

\section{Keywords}

Digital communication, Society, Social transformation, Information technologies, Digital revolution, Information ecosystem, Social networks, Media, Media ecology.

Scolari, Carlos A. "Comunicación digital. Recuerdos del futuro". El profesional de la información, 2012, julio-agosto, v. 21, n. 4 , pp. 337-340.

\section{La revolución digital}

En la segunda mitad del siglo XX los avances tecnológicos en el campo de los microprocesadores, la difusión capilar de las redes de intercambio de datos y el desarrollo de nuevas interfaces generaron un cambio radical en la vida humana similar al que, dos siglos antes, había producido la máquina de vapor. Si la máquina inventada por James Watts dio lugar a la Revolución industrial, las interfaces de Steve Jobs y las redes de Tim Berners-Lee abrieron el camino de la Revolución Digital ${ }^{1}$. La humanidad ya había vivido otros cambios en las tecnologías de comunicación, como el paso del papiro al 
codex de pergamino o el descubrimiento de la imprenta por parte de Johannes Gutenberg en el siglo XV, pero en esta ocasión los cambios fueron mucho más radicales.

Por una parte, la imprenta tardó cuatro siglos en convertir al libro en un producto barato y al alcance de todos los ciudadanos. Si bien las elites intelectuales aprovecharon inmediatamente las ventajas del soporte impreso -la revolución científica o la fractura del Cristianismo fueron algunas de sus consecuencias- recién en el siglo XIX el libro fue efectivamente un objeto al alcance de las masas. A las tecnologías digitales les bastó sólo una generación para modificar todos los ámbitos de la vida social, desde la educación hasta la política, pasando por la economía, la cultura, el arte o las ciencias. Hoy resulta difícil pensar en esa rápida transición y ponerse en la situación de esa generación que vivió a caballo entre el siglo XX y el XXI. En pocos años la mayor parte de sus actividades fueron rediseñadas -a menudo de manera traumática- por la irrupción de las entonces llamadas "nuevas tecnologías de la información y la comunicación" (o TICS). Formas de comunicación que venían de los siglos anteriores se extinguieron en pocos años, al mismo tiempo que emergieron nuevas experiencias de producción, intercambio y consumo informativo.

La digitalización -esto es, la reducción de todos los contenidos a una masa de bits- facilitó la manipulación textual. El nuevo texto digital era maleable, dúctil y fácil de enlazar con otros textos. El hipertexto, un concepto que hasta ese momento tenía un carácter casi utópico, se convirtió en el espacio textual por excelencia. Otros conceptos como remix y mashup -hoy casi olvidados ya que sólo sobreviven en algunos diccionarios técnicos- nacieron precisamente en este período, cuando millones de consumidores se lanzaron a explorar las posibilidades combinatorias de las textualidades digitalizadas. Se podría decir que todas las formas textuales contemporáneas descienden del texto digital de finales del siglo XX. Además, la digitalización favoreció la circulación de esos mismos textos en las redes globales. Los fenómenos de comunicación viral se pusieron a la orden del día: cualquier contenido tardaba pocos segundos en diseminarse a lo largo y a lo ancho del planeta.

Los grandes medios de difusión lucharon denodadamente por adaptarse a las nuevas reglas del juego y sobrevivir en un entorno cada vez más hostil

\section{Un nuevo ecosistema para una nueva sociedad}

La aparición de nuevas formas interactivas y colaborativas de comunicación implicó grandes cambios en el ecosistema de medios. Las nuevas especies mediáticas modificaron las relaciones de un ecosistema donde los medios masivos -denominados broadcasting por entonces- llevaban la voz cantante. Las nuevas formas de comunicación eran grandes depredadoras de la atención: si antes los consumidores dedicaban mucho tiempo a un puñado de medios (prensa, radio, televisión) en pocos años comenzaron a dedicar poco tiempo a muchos medios (webs, redes sociales, videojuegos, blogs, dispositivos móviles, etc.). Los grandes medios de difusión lucharon denodadamente por adaptarse a las nuevas reglas del juego y sobrevivir en un entorno cada vez más hostil. Algunos medios consiguieron subsistir mientras que otros, a pesar de los esfuerzos por adaptarse, se extinguieron. Dado que ha sido proceso muy investigado en los últimos años y todos los lectores saben cómo terminó, no insistiré con mayores detalles al respecto.

Las nuevas formas de comunicación participativas y colaborativas no sólo modificaron el ecosistema mediático: también dejaron sentir su influencia en campos como la educación, la política o el arte. La escuela fue quizá la institución que más tardó en adaptarse al nuevo ecosistema de medios. Durante décadas esta institución nacida al amparo de dos revoluciones (la francesa y la industrial, ambas a finales del siglo XVIII) siguió anclada en sus protocolos y modalidades de enseñanza-aprendizaje, lo cual fue generando un creciente descontento entre todos los afectados. Mientras otros ámbitos se adaptaron rápidamente a las nuevas condiciones tecnológicas, hasta bien entrado el siglo XXI la escuela y su hermana mayor, la universidad, tuvieron una actitud a menudo refractaria, no tanto hacia lo tecnológico sino hacia la nueva pedagogía que las plataformas colaborativas traían consigo.

\section{La escuela y la universidad tuvieron una actitud a menudo refractaria hacia la nueva pedagogía}

Los movimientos contestatarios acunados por las llamadas redes sociales a principios del siglo XXI merecen una profundización. Si bien en un primer momento se pensó que existía una relación causal entre la difusión de las plataformas de comunicación y las rebeliones juveniles que hicieron sentir su voz en las plazas de las principales ciudades del planeta, posteriores estudios demostraron que esas redes eran sólo un componente más de un complejo movimiento social. De todas formas, todos los historiadores del período coinciden en que, sin esas plataformas de comunicación, los movimientos no hubieran alcanzado ni la visibilidad ni la rapidez de difusión que efectivamente tuvieron. Por otra parte, conviene recordar la doble lógica que afectó a estos procesos sociopolíticos: se trató de movimientos que, si bien fracasaron a corto plazo, a largo término consiguieron imponer sus ideas y valores al resto de la sociedad.

\section{Evolución de la investigación}

La investigación de la comunicación también fue embestida por las nuevas tecnologías colaborativas y participativas. Casi un siglo de investigación sobre los mass media debió ser revisada y puesta al día para poder comprender las mutaciones que atravesaba el sistema de medios. Las teorías a disposición de los investigadores era precisamente construcciones analíticas pensadas para el broadcasting. La actitud de los investigadores de finales del siglo $X X$ se puede resumir en dos posiciones antagónicas. Por un lado estaban los que sostenían que los nuevos medios no tenían nada de nuevo; para ellos las redes digitales eran una estación más 


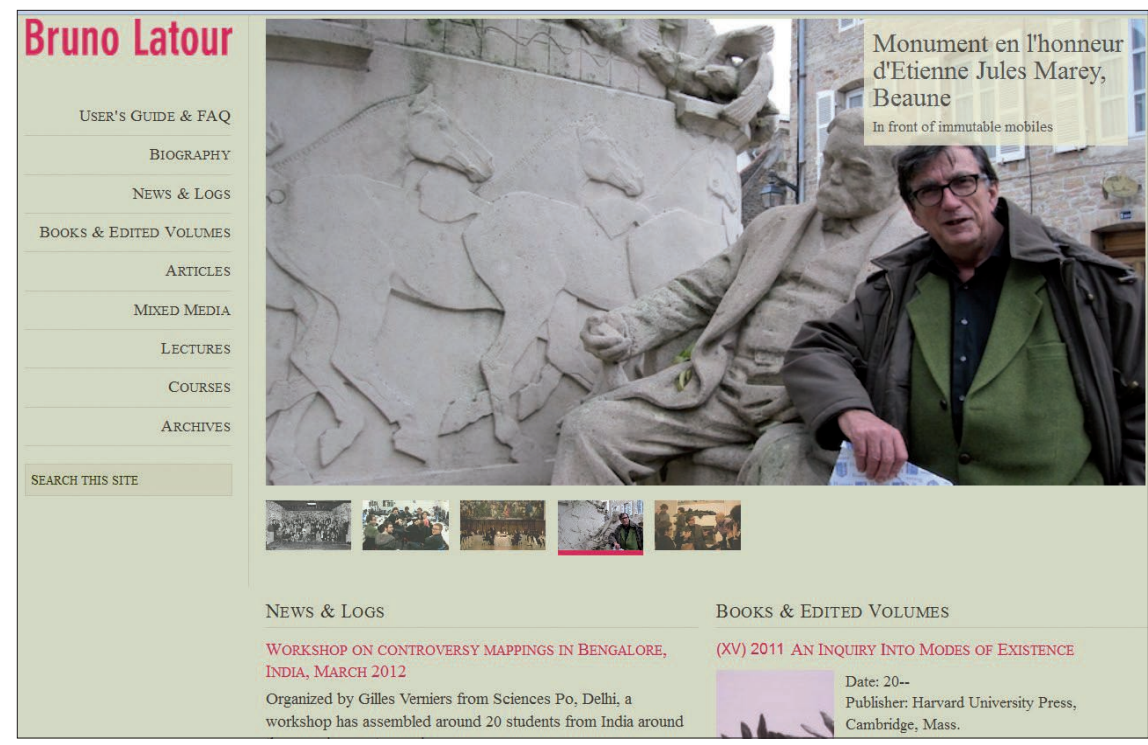

http://www.bruno-latour.fr

de la secuencia cine-radio-televisión. En este caso las teorías de los medios masivos eran consideradas más que suficientes para investigar las nuevas formas de comunicación. En el otro extremo se encontraban los que pensaban que los new media decretaban la obsolescencia de las teorías de los mass media y, por lo tanto, era necesario pensar en nuevos paradigmas. Esta cuestión de los nuevos paradigmas fue quizá uno de los grandes mitos de finales del siglo XX: si bien muchos los mencionaban en sus discursos teóricos, pocos comprendían realmente de qué estaban hablando. Conceptos como complejidad, caos, emergencia o meme se utilizaron de manera bastante impune en esos años. Sin embargo, podría decirse que en esa época se refundaron los estudios de la comunicación, recuperando muchos componentes del pasado y, al mismo tiempo, introduciendo nuevos conceptos, categorías de análisis e hipótesis de trabajo que constituyeron la base de los actuales paradigmas teóricos.

\section{Si bien a corto plazo los movimientos contestatarios fracasaron, luego consi- guieron imponer sus ideas y valores al resto de la sociedad}

¿Qué leían los investigadores de principios del siglo XXI? Aunque también se debería preguntar: ¿Cómo leían? Como ya se dijo, en ese momento se vivió el traumático pasaje desde una textualidad basada en interfaces orgánicas -el papel impreso- a las interfaces digitales. Precisamente en este período comenzó el proceso de digitalización y democratización del saber científico que llevó a la quiebra a las grandes editoriales especializadas en la publicación de journals académicos. Respecto a la primera pregunta -¿Qué leían los comunicólogos de principios del siglo XXI?- resulta imposible reconstruir la bibliografía nacida al calor de las redes digitales: miles de libros y artículos inundaron en pocos años las pantallas de los investigadores. Parte de esa producción teórica es prácticamente irrecuperable: a pesar de los emuladores de última generación, muchos textos publicados en formatos digitales hoy inexistentes -como el PDF- son de muy difícil acceso por la desaparición del hard- ware y los programas necesarios para abrirlos.

\section{Algunos referentes}

Entre los principales referentes teóricos del período emerge el nombre de Manuel Castells (1996-98, 2009), quizá el sociólogo que mejor logró procesar lo que estaba pasando en la sociedadred (el concepto es del mismo Castells). Desde la filosofía, un autor muy citado por entonces era el francés Pierre Lévy (1999, 2001), considerado como una de las voces de referencia en el campo de la naciente ciberfilosofía. Respecto a los cambios en los receptores y la aparición de nuevas prácticas textuales al margen del sistema de broadcasting, los trabajos del estadounidense Henry Jenkins (1992, 2006a, 2006b) tuvieron una gran repercusión en el mundo académico; la psicología de las redes encontró en Sherry Turkle $(1997,2012)$ a una de sus más destacadas analistas. Las relaciones entre viejos y nuevos medios fueron repensadas por autores como Alejandro Piscitelli (1995, 1998), Jay-David Bolter y Ricard Grusin (2000), Roger Fidler (1997), Lev Manovich (2002) y Carlos A. Scolari (2008), todos ellos influenciados en mayor o menor medida por uno de los más célebres y polémicos intelectuales del siglo XX: MarshaII McLuhan (1962, 1964). Pensadores a menudo lejanos del entorno académico como Kevin Kelly (1994), Steven Johnnson (2006) y Howard Rheingold (1992, 2000, 2003, 2012) también aportaron lo suyo para la comprensión de las nuevas formas de comunicación digital interactiva.

Los investigadores se dedicaron a discutir sobre los efectos de las redes digitales en el cerebro de los jóvenes

\section{Las redes}

Un debate destacado de ese período llevó a los investigadores de las redes sociales a mantener interesantes discusiones con los expertos en ciencias cognitivas y neurociencias. A comienzos del siglo XXI no pocos temían que el uso de las redes modificara, en un sentido negativo, la conformación del cerebro humano. Lo mismo que Platón había dicho sobre la escritura cuatro siglos antes de Cristo ahora volvía dos milenios más tarde en clave digital. Algunos como Nicholas Carr (2011) llegaron a preguntarse: ¿Nos están volviendo estúpidos las redes? En realidad este debate no era nuevo en el ámbito de la comunicación: cada vez que un nuevo medio aparecía en el ecosistema de la comunicación no tardaban en aparecer sus defensores y sus detractores. Si a lo largo del siglo XX los investigadores de los medios se habían entretenido debatiendo sobre los efectos de la televisión en los niños, sus alumnos -ya convertidos a su vez en prestigiosos académicos-se dedicaron a discutir sobre los efectos de las redes digitales en el cerebro de los jóvenes.

Pero también se debe reconocer que en este período a caballo entre el siglo XX y el XXI se fue configurando un campo 
del conocimiento que dejaría su huella en la ciencia contemporánea: la teoría de las redes. Pioneros como Albert-László Barabási (2002, 2010) y Bernardo Huberman (2001) abrieron un camino al cual no tardarían en sumarse investigadores de todas las disciplinas. Si a mediados del siglo XX todo era sistema o estructura, a comienzos del siglo XXI todo pasó a ser red. Como cualquier adolescente sabe, los aportes de la teoría de las redes contribuyeron a refundar las ciencias sociales y abrieron nuevos horizontes en casi todos los sectores de la ciencia, desde la biología hasta la economía.

Ser un investigador o profesional de la comunicación entre los siglos XX y XXI no era fácil, pero seguramente era emocionante, casi como ser pintor en la Florencia del siglo XV o ingeniero en la Birmingham del siglo XIX. El sólido mundo en que se habían formado varias generaciones de profesionales e investigadores, con sus certezas teóricas y sus protocolos de trabajo, se disolvió en un par de décadas para dar lugar a una de las más grandes transformaciones que vivió el género humano.

\section{Nota}

1. Se recuerda que, siempre al final del siglo XX, algunos investigadores cuestionaban la llamada "teoría heroica de la invención" que unía a cada dispositivo el nombre de su inventor, cuando en realidad se trataba de creaciones colectivas. Una nueva tecnología nunca es el fruto de una mente genial sino de las interacciones de un conjunto social. Sería conveniente que los jóvenes estudiosos de las relaciones entre tecnología y sociedad releyeran esos trabajos críticos publicados entre 1980-2020 encuadrados bajo el nombre de la Social construction of technology (SCOT) y la Teoría del actor-red del francés Bruno Latour (2005).

\section{Bibliografía}

Para un primer acercamiento a la reflexión sobre la comunicación digital, se recomiendan las siguientes obras publicadas entre los siglos XX y XXI:

Barabási, Albert-László. Linked: The new science of networks. Cambridge, MA: Perseus Publishing, 2002.

Barabási, Albert-László. Bursts: The hidden pattern behind everything we do. New York: Dutton Books, 2010.

Bolter, Jay-David; Grusin, Ricard. Remediation: understanding new media. Cambridge, MA: MIT Press, 2000.

Carr, Nicholas. The shallows. What the internet is doing to our brains. New York, NY: W. W. Norton \& Company, 2011.

Castells, Manuel. The rise of the network society, The information age: Economy, society and culture Vol. I. Cambridge, MA; Oxford, UK: Blackwell, 1996.

Castells, Manuel. The power of identity, The information age: Economy, society and culture Vol. II. Cambridge, MA; Oxford, UK: Blackwell, 1997.

Castells, Manuel. End of millennium, The information age: Economy, society and culture Vol. III. Cambridge, MA; Oxford, UK: Blackwell, 1998.

Castells, Manuel. Communication power. Oxford/New York: Oxford University Press, 2009.
Fidler, Roger. Mediamorphosis: understanding new media. Thousand Oaks, CA: Pine Forge Press, 1997.

Huberman, Bernardo. The laws of the Web. Patterns in the ecology of information. Cambridge, MA: MIT Press, 2001.

Jenkins, Henry. Textual poachers: television fans \& participatory culture. New York, NY: Routledge, 1992.

Jenkins, Henry. Convergence culture: where old and new media collide. New York, NY: New York University Press, 2006a.

Jenkins, Henry. Fans, bloggers, and gamers: exploring participatory culture. New York, NY: New York University Press, 2006b.

Johnson, Steven. Everything bad is good for you: how today's popular culture is actually making us smarter. New York, NY: Penguin Group, 2006.

Kelly, Kevin. Out of control: the new biology of machines, social systems, \& the economic world. Cambridge, MA: Perseus Publishing, 1994.

Latour, Bruno. Reassembling the social: an introduction to actor-network-theory. New York, NY: Oxford University Press, 2005.

Lévy, Pierre. Collective intelligence: mankind's emerging world in cyberspace. New York, NY: Basic Books, 1999.

Lévy, Pierre. Cyberculture. Minneapolis, MN: University Of Minnesota Press, 2001.

Manovich, Lew. The language of new media. Cambridge, MA: MIT, 2002.

McLuhan, Marshall. The Gutenberg galaxy. Toronto: University of Toronto Press, 1962.

McLuhan, Marshall. Understanding media: the extensions of man. New Cork, NY: McGraw Hill, 1964.

Piscitelli, Alejandro. Ciberculturas. Buenos Aires: Paidos, 1995.

Piscitelli, Alejandro. Post/television: ecología de los medios en la era de internet. Buenos Aires: Paidos, 1998.

Rheingold, Howard. Virtual reality: The revolutionary technology of computer-generated artificial worlds - and how it promises to transform society. New York, NY: Simon \& Schuster, 1992.

Rheingold, Howard. The virtual community: homesteading on the electronic frontier (Revised edition). Cambridge, MA: MIT Press, 2000.

Rheingold, Howard. Smart mobs: the next social revolution. New York, NY: Basic Books, 2003.

Rheingold, Howard. Net smart: how to thrive online. Cambridge, MA: MIT Press, 2012.

Scolari, Carlos A. Hipermediaciones. Elementos para una teoría de la comunicación digital interactiva. Barcelona: Gedisa, 2008.

Turkle, Sherry. Life on the screen: identity in the age of the internet. New York, NY: Simon \& Schuster, 1997.

Turkle, Sherry. Alone together: Why we expect more from technology and less from each other. New York, NY: Basic Books, 2012. 